\title{
Following up outpatients by telephone: pilot study
}

\author{
Badal Pal
}

The potential of the telephone in routine medical care has not been widely explored. ${ }^{12}$ On a detailed questionnaire on follow up by telephone that canvassed the views of 275 outpatients, $160(80 \%)$ stated they would be willing to accept this. ${ }^{3}$ We evaluated the role and value of follow up by telephone in the continuing care of rheumatology outpatients.

\section{Patients, methods, and results}

Subjects were selected during routine follow up at the rheumatology outpatient clinic. All patients were given a verbal and a written explanation of the aims of the service. An initial detailed clinical assessment and investigations were undertaken to determine patients suitability for follow up by telephone. Those considered unsuitable because of clinical circumstances, age, cognitive or hearing impairment, or language problems were excluded. Approval for the study was granted by the hospital management.

All but three of the 173 suitable subjects agreed to follow up by telephone at their next review. During the first year of the project 52 patients with rheumatoid arthritis, 27 with soft tissue rheumatism, 22 with degenerative arthritis, 18 with connective tissue disease, 13 with polymyalgia, 9 with ankylosing spondylitis, 4 with gout, and 25 with miscellaneous disorders were followed up by telephone.

Patients were telephoned on the appointed date and time (with few exceptions). Their progress was discussed, any changes in the condition or treatment were noted, and they were given the results of any investigations undertaken at their last clinic attendance. Any necessary advice (including changes in treatment) was given on the telephone. Telephone conversations lasted an average of 3.5 (range 1-15) minutes per patient. The main points of the discussion were relayed to the patient's general practitioner by letter; a copy was sent to the patient to avoid any misunderstanding. No important misunderstandings have occurred to date.

Twenty patients could not be contacted by telephone on the appointed date and time. They were either followed up by telephone in the next few days or sent an appointment to attend an outpatient clinic. Decisions made at follow up by telephone were not revised appreciably later, except for two patients with rheumatoid arthritis and two with lupus (one of whom required admission to hospital) who needed earlier clinic review because of flare up.

During the first year of the project one of the 170 patients died; this death was not unexpected. Thirty two patients could be discharged after follow up by telephone. A survey of patients' satisfaction with telephone follow up showed that they were generally in favour (table): it could save time and money, might be more relaxed and less stressful, and obviated problems over transport and waiting. Perceived disadvantages were that telephone follow up was impersonal, patients might feel uncomfortable

\begin{tabular}{|c|c|c|c|}
\hline Questions & $\begin{array}{l}\text { Positive } \\
\text { response }\end{array}$ & $\begin{array}{l}\text { Negative } \\
\text { response }\end{array}$ & $\begin{array}{c}\text { No } \\
\text { response }\end{array}$ \\
\hline $\begin{array}{l}\text { Did you receive enough information about the project before } \\
\text { being contacted by telephone? }\end{array}$ & $99(83)$ & $19(16)$ & $2(2)$ \\
\hline $\begin{array}{l}\text { Were you satisfied with the discussion and advice given on the } \\
\text { telephone? }\end{array}$ & $108(90)^{\star}$ & $7(6)$ & $5(4)$ \\
\hline Is follow up by telephone better or worse than clinic follow up? & $92(77) \dagger$ & $21(18)$ & $6(5)$ \\
\hline $\begin{array}{l}\text { After follow up by telephone you were sent a clinic appointment. } \\
\text { Did you receive this notification? }\end{array}$ & 85 (71) & $18(15)$ & $17(14)$ \\
\hline $\begin{array}{l}\text { Would telephone follow up alternated with clinic appointments be } \\
\text { acceptable to you? }\end{array}$ & $99(83)$ & $16(13)$ & $8(7)$ \\
\hline
\end{tabular}

*Very satisfied=62, satisfied=46. $†$ Better=61, no different $=31$.

discussing things over the telephone, the possibility of misunderstanding was greater, and hearing and language problems were more likely.

\section{Comment}

A telephone follow up clinic is a logical extension of the sort of patient friendly services that an NHS trust should provide. The level of satisfaction with the service (90\% satisfied or very satisfied) was comparable to that shown by those attending clinic (94\%) at an audit undertaken concurrently at the same time. Most patients considered that benefits outweighed disadvantages. Disadvantages can be overcome or minimised by careful selection of patients for telephone follow up.

"Telemedicine" has been assessed in general practice, with encouraging results. ${ }^{45}$ Telephone follow up may have a role in many hospital specialties, particularly those such as dermatology and neurology in which many patients have chronic conditions. Once established as a routine service, telephone follow up may result in shorter lists for review patients, more slots for new referrals, reduction in non-attendance at clinics, and consequent saving of NHS resources.

The general practitioners of all the patients offered follow up by telephone in this project accepted the service. Formal surveys of their views are underway.

I thank Mrs Joan Kay and Miss Alison Webb for secretarial assistance and Miss Frances Carey and Mrs Maureen Silcock at the department of clinical audit and business management, South Manchester University Hospitals Trust, for help with designing and analysing the patient questionnaires.

Contributors: BP planned and carried out the study, wrote the paper, and is guarantor of this report.

Funding: None.

Conflict of interest: None.

Wootton R. Telemedicine: a cautious welcome. BMJ 1996;313:1375-7.

2 Rao JM. Follow up by telephone. BMJ 1994;309:1527-8.

3 Pal B, Morris J. Will patients accept follow up by telephone? A survey of ambulatory patients' attitudes. BrJ Rheumatol 1996;35(suppl 1):A250.

4 Hallam L. Organisation of telephone services and patients' access to doctors by telephone in general practice. BMJ 1991:302:629-32.

5 South Wiltshire Out of Hours Project (SWOOP) Group. Nurse telephone triage in out of hours primary care: a pilot study. BMJ 1997;314:198-9.

(Accepted 1 November 1998)
South Manchester University Hospitals NHS Trust, Withington Hospital, Manchester M20 2LR Badal Pal, consultant rheumatologist bpal@fs1.with.man. ac.uk

BMJ 1998;316:1647 